\title{
Economic and Political Determinants of Budget Deficits in the European Union: A Dynamic Random Coefficient Approach
}

\author{
ALI BAYAR \\ BRAM SMEETS \\ CESIFO WORKING PAPER NO. 2546 \\ CATEGORY 5: Fiscal Policy, MaCrOECONOMICS AND GROWTH \\ FEBRUARY 2009

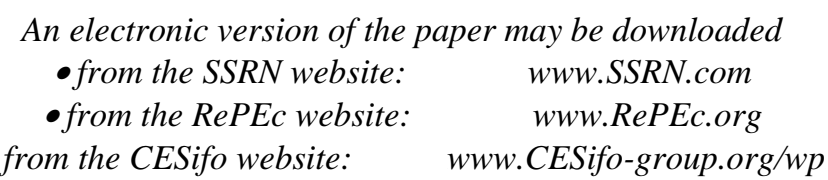




\title{
Economic and Political Determinants of Budget Deficits in the European Union: A Dynamic Random Coefficient Approach
}

\begin{abstract}
This paper formulates a dynamic Random Coefficient Model (RCM) to consider a set of popular determinants of public deficits in the EU-15 over the period 1971-2006, both at a country-specific level and from a population-wide perspective. Although the extent of government deficits and debt has been one of the most debated macroeconomic issues in recent times, the models trying to capture the explanatory powers driving these deficits typically estimate models that pose the strict assumption of homogeneity on the coefficients over all countries in the model. The sensibility of this assumption will be investigated, with results showing that an increase in the degree of heterogeneity leads to an improvement in the model fit and provides additional information to nuance the effects of the explanatory variables. In this way, the paper exposes a limited degree of partisanship over all countries under consideration, but on the other hand provides evidence for opportunistic behaviour of policymakers in the major part of the sample. The effect of institutional changes following the enforcement of the Maastricht Treaty varies over the countries and is related to the necessity of budgetary consolidation.
\end{abstract}

JEL Code: C11, E6, H6, H87.

Keywords: fiscal policy, European Monetary Union, Random Coefficient Model, Bayesian Analysis.

Ali Bayar

Free University of Brussels

EcoMod

Avenue F.D. Roosevelt, 50

C.P. 140

Belgium - 1050 Brussels

Ali.Bayar@EcoMod.net
Bram Smeets

EcoMod

Belgium - Brussels

bram.smeets@ecomod.net 


\section{Introduction}

The extent of government deficits and debt has been one of the most debated issues in economics in recent years. Whereas budget deficits were initially considered to be a merely macroeconomic phenomenon, starting from the 1980s a new field in Political Economics developed, casting light on the topic from both economic and political perspectives. This movement was inspired in particular by the notion that many industrialised countries had been facing considerable budget deficits following the first oil crisis in 1973. Whereas existing economic theory would predict these deficits to vanish during more prosperous times, in most countries they were persistent over the following decades. As a consequence, debt levels had been increasing steadily over the same period and besides, the deficits and debt levels varied in size among various countries facing similar economic conditions and shocks.

In order to explain the cross-country differences among the OECD-members, the existing, normative economic theory alone did not suffice. Therefore, political variables, such as the ideological characteristics or the degree of fragmentation of the government, and institutional factors, like certain aspects of the process of budget determination, were included as additional explanatory variables in models that tried to give a positive explanation for the observed patterns in deficits. At the same time, in Europe the process of integration towards an economic and monetary union took shape, and with the ratification of the Maastricht Treaty, signed by 15 members of the EU in 1992, the participating governments bound themselves to strict guidelines on their macroeconomic policy measures. In order to evaluate the appropriateness of the particular measures imposed, an extensive literature developed investigating their outcomes and consequences. Besides, almost simultaneously, in the US the Balanced Budget Rule was introduced, that imposed similar budgetary requirements and accordingly stimulated a parallel discussion on the effectiveness of fiscal constraints.

The quest for models explaining budget deficits from a positive perspective considerably gathered momentum over the last two decades, and debates on the issue of aging populations throughout the western world called for a further increase in attention for the determinants and consequences of persistent deficits on the one hand and successful, sustainable fiscal policies on the other. The literature on this topic can be categorised in various ways; firstly, according to the particular variables whose explanatory power is considered, with main emphasis on politically oriented variables - e.g. political stability, size of government, fragmentation of government - vs. institutional factors 
- e.g. type of budgetary procedures, negotiation power of unions etc. Second, a considerable number of contributions deal with the question whether political business cycles are present in the series of budget deficits. Besides, various regions have been under consideration, ranging from the $\mathrm{EU}$ or a selection of OECD countries to the developing world. For the former region, the impacts of the Maastricht Treaty and the Stability and Growth Pact on economic and budgetary performance have been analysed.

A natural alternative criterion for categorisation of the literature would be the employed methodology. However, it is remarkable that, in this respect, the lions share of existing works follows the same standards, to the extent that the vast majority of the literature analyses panel data consisting of pooled, country-specific time series ${ }^{1}$ and uses Ordinary Least Squares (OLS) methods to estimate these models. This similarity in estimation methods enhances the degree of comparability of the results, but at the same time raises the question whether it is the most appropriate method for drawing inference on the forces driving the budget deficit.

One of the assumptions underlying the use of Ordinary Least Squares methods is homogeneity of all observations. ${ }^{2}$ Many authors recognised that this assumption is rather strict and insensible, and as a way to add flexibility they therefore allow for heterogeneity in the constant term (i.e. they estimate fixed effect models) or model the error terms in greater detail, typically by allowing for serial or contemporaneous cross-sectional correlation. In general, the increased degree of heterogeneity is justified by results of the studies, showing that indeed the various countries and time periods under consideration possess different intercepts and error term behaviour. However, these approaches typically still impose homogeneity on the variables that we are most interested in in our analysis: the parameters of the explanatory variables. From an intuitive point of view, this assumption seems rather dissatisfactory in the context of this paper: is the impact of leftist governments in Sweden similar to those in Italy? Is the persistence of the budget deficit equal in Belgium and Luxembourg? As an extension to the existing attempts to incorporate heterogeneity in the model, it will be interesting to increase the degree of flexibility of these parameters and analyse the extent of similarity and vari-

\footnotetext{
${ }^{1}$ These datasets are often labeled Time Series Cross-Section (TSCS) data, and are characterised by their dimensions: observations are collected repeatedly over time and pooled together for a limited number of countries $N$, with the time series dimension $T$ typically being considerably larger than $N$.

${ }^{2}$ I.e. The parameter values are assumed to be constant across countries and the estimated error terms to have an identical homogeneous structure over the complete dataset.
} 
ability in their values across countries. The Random Coefficient framework is a particularly gentle method for carrying out such an analysis, because it allows the modeler to draw inference on population-wide and country-specific parameters at the same time. Especially when focusing on the EU, experiencing a high degree of interaction and interdependence between economies, this gives us a powerful tool to evaluate to validity of assumptions of homogeneity and analyse as an alternative the degree of heterogeneity together in one model.

This paper will focus on the 15 countries in the EU that signed the Maastricht Treaty, and analyses the similarities and differences in the impacts of various economic and political determinants of budget deficits. Using data ranging over the period 1971-2006, a Random Coefficient Model will be constructed, incorporating various variables that are selected in line with findings in the contemporary literature. Using this model, the presence of partisan or opportunistic behaviour by policymakers will be analysed, as well as the impacts that the Maastricht Treaty had on the budget deficits in the EU-15. In order to draw inference on the degree of heterogeneity among the countries, coefficients are simultaneously estimated on a population-wide level and as country-specific parameters. In the following section, an investigation of existing literature will be provided. Subsequently, the model specification will be elicited, and the data analysed. Section 5 gives an introduction and detailed outline of the Bayesian estimation methodology, followed by an analysis of empirical results in section 6 . The final section concludes our findings.

\section{Literature review}

The basic 'equilibrium' model proposed by Barro (1979) and Lucas and Stokey (1983) argues that in order to minimise distortions tax rates should be relatively constant over time and therefore spending and revenue shocks should be smoothed by budget deficits and surpluses. However, this normative economic argumentation of the 'tax-smoothing' model does not explain why the budget deficits that emerged during the oil crises in the 1970s persisted, and neither why countries facing similar economic shocks experienced very different paths of budget deficits. Alesina and Perotti (1995 and 1996) argue that economic theory alone cannot explain the issue and in an attempt to find positive explanations for the path of budget deficits, instead of normative prescriptions, one should therefore address the political and institutional aspects of the question. Various variables exist that are candidates to be included in such a model. 
In a seminal work, Roubini and Sachs (1989) consider the relation between deficits and the structure of the governments and in particular its fragmentation, finding that multiparty coalition governments have a higher tendency to develop large and persistent deficits. Besides, countries where governments have short tenures tend to have higher deficits on average. In a reexamination of these results, Edin and Ohlsson (1994) reveal the sensitivity of the former conclusion to the definition and dimension of the variable capturing government fragmentation, claiming that only minority governments have a particular tendency to develop large deficits, and differences between majority governments with different numbers of participating parties are insignificant. De Haan and Sturm (1994) found support for neither of the two hypotheses based on an investigation of the countries in the European Community in the 1980s, and conclude that there are no significant differences in explanatory power among single party majority governments, coalition governments and minority governments. In more recent literature, different definitions of the degree of fragmentation are considered and e.g. Volkerink and De Haan (2001) find that the number of spending ministers has stronger and more robust explanatory power than the number of parties in the government. Perotti and Kontopoulos (2002) find supportive results and show that the latter variable even turns insignificant.

Parallel to the discussion on political relations and their impact, a large part of the literature on deficits has focused on finding models that explain the behaviour of policy-makers by considering differences in ideological characteristics or by interpreting deficits as a strategic mean that can be used when seeking re-election. In this context, Franzese (2002) gives a comprehensive overview of existing views, distinguishing between two types of models that are generally used to explain and interpret the behaviour of politicians. Opportunistic models argue that policy is determined by electoral motivations: Politicians have no preferences of their own, based on a political conviction, but just follow policies which maximise their probability of winning the next elections. Political cycles depending on these policies typically show higher deficits in election years or shortly before, as a result of government giving bonuses to the electorate and trying to gain popularity right before the elections. In an empirical investigation of this question, Mink and De Haan (2005) find that during election years deficits tend to be higher, whereas in the year preceding the elections they are not. As a nuance to this finding, Andrikopoulos et al. (2004) focus on a larger time period and find that instead right-wing governments tend to be in favour of fiscal stabilisation during election times. 
Partisan models on the other hand emphasise policymakers' ideological motivations and argue that right- and left-wing parties follow different policies, at least partially determined by their ideological preferences. Related cycles should show different patterns in deficits depending on the ideological orientation of the government in office. Alesina and Roubini (1997) find no significantly higher deficits for left-wing governments as compared to other governments. Perotti and Kontopoulos (2002) show that ideology only influences the budget process via expenditures - transfers in particular -, and find no significant evidence that it leads to differences in surpluses or deficits. Volkerink and De Haan (2001) use an ideology index and find similar results. Mulas-Granados (2003) analyses the influence of political variables on the decomposition of the government budget, and finds that left wing governments are not directly associated with higher or lower deficits, but do manage to have more successful fiscal adjustments in the second half of the 1990s.

Next to the division of political power and the behavioural characteristics of policymakers, a third category in the literature on deficits approaches the issue from an institutional perspective. Since the early 1990s, several institutional and political changes have limited the freedom of the European national governments (and US state governments) to pursue a discretionary budgetary policy. Being subject to strict rules and guidelines imposed by the ratification of the Maastricht Treaty, the implementation of the Stability and Growth Pact and the introduction of the Euro, many countries managed to escape from the persistent and massive deficits that had been common during the past decades. Nevertheless, the sensibility and appropriateness of these measures has been subject to a broad debate. Buiter et al. (1993) and Roubini (1995) examine the relevance of fiscal constraints and claim that rigid fiscal rules deprive the policy maker of an important tool to stabilise output and smooth tax distortions over time. Ballabriga and Martinez-Mongay (2005) evaluate the sustainability of public finances in a country set including the EU, both before and after 'Maastricht'. They find that the major part of member states in the EU pursued sustainable fiscal policies both before and after the enforcement of the Maastricht-criteria and consequently question the necessity of the rigid rules of the SGP. In general, the recent macroeconomic literature on fiscal policy is remarkably rich and especially in relation to the European integration process, many contributions have brought better understandings but also larger contradictions concerning the determinants of public deficits.

While a broad scala exists of approaches to find different types of deter- 
minants for the magnitude of deficits, their degree of adaptation towards a sustainable level or their duration, this diversity does not apply to the employed methodology. Particularly driven by the type of data available, the typical approach uses Time Series Cross Section (TSCS) formulations to estimate pooled models, that assume that parameters and coefficients are constant over all countries in the set. This is a rather rigid assumption, and although many modelers have recognised the need for additional flexibility in the model, usually this is only implemented in the estimation of the error term, where heterogeneity may be allowed for or serial or spatial correlation may be modeled. Even more general, Beck and Katz (1995) show that the vast majority of contributions in the field of comparative Political Economics has adopted pooled OLS estimation as a standard. They show that especially in TSCS data sets, drawing inference based on the resulting statistics can lead to a considerable bias towards the conclusion that parameters are significant. As a solution, they suggest the use of Panel Corrected Standard Errors (PCSE) to account for the particular spatial relations that are present in political/macroeconomic TSCS data. As a follow-up in the attempts to model heterogeneity, the Random Coefficient Framework is a very suitable approach. Rather then focusing on the error term solely, it addresses the actual coefficients in the model as well, and allows the modeler to combine individual-specific estimations with overall mean findings, and consequently enables the individual estimators to borrow strength from each other.

\section{Model Specification}

In our analysis, we model the determinants of the primary budget deficit, $D E F_{i, t}$ in the following specification:

$$
\begin{aligned}
D E F_{i, t}= & \beta_{0}+\beta_{1, i} D E F_{i, t}+\beta_{2, i} \Delta U B_{i, t}+\beta_{3, i} \Delta y_{i, t}+\beta_{4, i} D R B_{i, t} \\
& +\sum_{j} \beta_{(4+j), i} P I_{j, i, t}+\nu_{i, t}, i=1, \ldots, N, t=1, \ldots, T .
\end{aligned}
$$

Equation (1) defines a time series cross-sectional (TSCS) model over countries $i$ and years $t$, where $D E F_{i, t}$ is the fiscal deficit-to-GDP ratio, defined as the ratio of between net lending including interest and the current GDP. $\Delta U B_{i, t}$ is the change in the unemployment rate, $\Delta y_{i, t}$ is the change in the GDP growth rate, $D R B_{i, t}$ is the change in real debt-servicing costs, and $P I_{j, i, t}$ are various political and institutional variables that will be specified later. Finally, $v_{i, t}$ denotes the error term. 
DRB is defined as

$$
D R B_{i, t}=\Delta\left(r_{i, t}-p i_{i, t}-g_{i, t}\right)\left(D e b t_{t-1} / G D P_{i, t-1}\right),
$$

where $\Delta$ denotes the first difference operator, $r$ is the long-term nominal interest rate, $\pi$ is the inflation rate, $g$ is the real GDP growth rate, and $D_{e b t_{t-1}} / G D P_{i, t-1}$ is the lagged debt-to-GDP ratio. The set of political data $P I$ consists of the following variables:

- Ideo ${ }_{i, t}$ represents the ideological complexion of the government. Following the methodology established by Woldendorp, Keman, and Budge (1998) the variable attempts to account for the relative strength of parties in government with reference to the left-right dimension, through a five-point scale in which the proportional shares of the left, center and right oriented parties are transformed into scores (1 to 5) representing the degree of dominance of either party both in parliament and government. It takes the value 1 for right-wing governments, 2 for center-right governments, 3 for a balanced situation, 4 for center-left governments, and 5 for left-wing governments. The index is first compiled on a monthly basis and then transformed into an annual index as a weighted average of the monthly values. The index is introduced in the regressions as a single variable and also, alternatively, in the form of dummy variables (IDEO1, IDEO2, IDEO3, IDEO4, and IDEO5, where we take as reference the balanced situation represented by IDEO3). As main source for the index we use Woldendorp, Keman and Budge (1998), although we made adaptations according to our own judgement - based on historical data - and updated the index to cover the entire period 1970-2006.

- $E l e c_{i, t}$ is a dummy variable taking on value 1 in years during which a country had (one or more) parliamentary elections and 0 otherwise.

- $\delta_{M}$ is a temporal dummy variable, capturing the change in the deficit resulting from the institutional developments following the Maastricht Treaty. It takes the value of 1 starting in 1994 and all years afterwards, reasoning that the treaty admittedly went into force slightly earlier, on 1 November 1993, but its effects on the macro economies are likely to become present during the first year following its ratification. Besides, as of this year the convergence criteria for potential member states applied. 
To elucidate the estimation framework of our TSCS model, assume that all $K$ explanatory variables are stored in the $N T \times K$ matrix $X$, and our dependent variable in the $N T \times 1$ vector $y$. The most common approach to estimate the relation between the dependent and explanatory variables is by assuming that the parameters are fully pooled over all countries:

$$
y_{i, t}=X_{i, t} \beta+v_{i, t} ; i=1, \ldots, N ; t=1, \ldots, T
$$

This corresponds to an interpretation of the variables $\beta_{j, i}, j=1, \ldots, K$ in equation 1 to be constant over the countries $i$. As an addition, in the fully pooled model, one assumes $\varepsilon_{i, t} \sim N\left(0, \sigma^{2}\right)$. The assumptions that all parameters $\beta_{j}$ are identical across countries, and the errors homoscedastic, are rather strong. Therefore, as a way of increasing the degree of flexibility, the modeler often allows for some country-specific components in his model, typically by allowing the constant to vary (i.e. formulate a fixed-effects model). Besides, the variance of the residuals is often allowed to vary over countries or time, and specific error term structures are assumed, in order to model its development over time, or its dependencies between countries. ${ }^{3}$ Usually all these models can be estimated using (an adaptation of) OLS methods. However, even after incorporating the adaptations to the fully pooled model described above, the assumptions underlying the model remain rather strict, and impose that the effects of e.g. political variables like ideology are identical across countries. Loosening this assumption, one can formulate a model of the form

$$
y_{i, t}=X_{i, t} \beta_{i}+v_{i, t} ; i=1, \ldots, N ; t=1, \ldots, T .
$$

Now, we estimate country specific parameters $\beta_{i}$, but the modeler can still decide whether to allow for interdependencies between countries or not. Assuming that there exist none is equivalent to estimating country-specific OLS regressions. Although this would allow for considerably more flexibility, this advantage comes at the expense of estimation accuracy, since the number of observations per regression will be reduced by a factor $N$. Between the two options of full pooling vs. not allowing for relations between countries, there exists a trade-off of flexibility vs. accuracy in the estimation.

This trade-off can be circumvented by employing another methodology: even when estimating country-specific parameters like in equation 4, one can allow these parameters to be related. A gentle approach in our attempt to model cross-section dependence is the formulation of a Random Coefficient

\footnotetext{
${ }^{3}$ Well known examples that are particularly popular in Political Economics are Panel Corrected Standard Errors (PCSE, c.f. Beck and Katz, 1995), or robust covariance estimation (c.f. Wooldridge, 2002)
} 
Model (RCM), as proposed by $\operatorname{Swamy}(1970)$. In equation 4, one now assumes $\beta_{i}=\bar{\beta}+\alpha_{i}$, such that:

$$
y_{i, t}=X_{i, t} \bar{\beta}+X_{i, t} \alpha_{i}+v_{i, t} ; i=1, \ldots, N ; t=1, \ldots, T .
$$

This formulation brings several advantages. In the first place, it allows for country-specific parameters, while at the same time taking advantage of the fact that there is information available on several units. As will be shown later, the degree of similarity between countries, as measured by covariances between the country specific parameters, will determine the relative impacts of $\bar{\beta}$ and the country-specific deviation $\alpha_{i}$ on the actual parameter $\beta_{i}$. Second, the size of these two components will reveal a great deal of information on the comparability of the political forces playing in different countries and, when modeled over time, can also be used to reveal paths of convergence. Finally, one will be able to test the hypothesis $H_{0}: \alpha_{i}=0, \forall i$, versus the alternative that indeed the parameters differ per country.

\section{Economic and Political Data: Stylised facts}

Columns 2-5 of table (1) show the average values of the public balance per country, where the sample period is divided in decades and besides columns 6 and 7 present a pre- and post-Maastricht era. Note that in this table, the budget balance as difference between revenues and expenditures is presented, with a positive value corresponding to a budget surplus, whereas our dependent variable in the regression analyses will be the budget deficit. The figures in table 1 exhibit the notion that almost all countries faced considerable and persistent budget deficits during the first two decades under consideration.

During the 1970s and the 1980s, only Luxembourg and the UK were able to improve their average between the decades; Luxembourg even managed to have budget surpluses in 17 years out of the first 20 years under consideration in our sample, while the UK still faced deficits in 17 years over the two first decades, but managed to cut back their deficits in the six consecutive years after 1984, and switch to a surplus at the end of that period. Belgium and Italy faced the highest and most persistent deficits, having values well over five percent in at least 19 consecutive years after 1974. Ireland also experienced deficits in all years, with slightly lower levels on average, whereas Greece did particularly badly during the 1980s, with values exceeding the 10 percent in the second half. The Scandinavian countries were an exception concerning their budgetary policies, since they managed to control their deficits after the deterioration in the second half of the 1970s, and they were able to present sharp improvements after 1982, leading to surpluses by the 
time of 1986. Whereas Sweden and Denmark did experience deficits of up to seven percent in the period in between, Finland even outperformed them by only having surpluses in the first two decades. The remaining European countries did not manage to pursue this anti-cyclical policy with deficits as smoothing instrument and faced persistent deficits after 1974. Spain and the Netherlands faced deterioration after 1973, reaching deficit levels well over six percent in the early 1980s, and were stuck to values that were just slightly smaller afterwards. Austria experienced a comparable development, although its peak was smaller, just over four percent, whereas Portugal went through worse times and faced deficits ranging between four and 9,4 percent after 1974. Finally, Germany and France succeeded to keep their deficits under three percent in most years, although Germany did not experience any years with budget surpluses between 1974 and 1988, and France experienced just two years with very small surpluses over the period from 1974 until today.

$<<<$ Insert table (1) about here $>>>$

This latter observation makes France rather exceptional: whereas all countries started to pursue policies of fiscal consolidation to improve their budgetary situations, particularly after 1993, the year in which the Maastricht Treaty was ratified, this led most of them to a state of budget surpluses, except for France, Spain, Portugal and Italy. The countries that did manage to switch their deficits into surpluses experienced a peak in their budgetary situation in 2000 or 2001, and saw a decrease following the economic deterioration in the early 2000s.

As one of the considered determinants, this paper will focus on the correlation between the extent of budget deficits and the ideological convictions represented in the government. Table (2) presents an overview of the proportion of time spent in every ideological category, where category 1 corresponds to a right-wing government, and category 5 to a left wing-government, as explained in the previous section. Luxembourg, outperforming all other countries by almost solely experiencing surpluses rather than deficits, had no left wing or center-left governments, but spent most of the years under consideration having neutral governments. This also holds for Finland, the other country that spent most of the time during last decades in a situation of budgetary surplus. It did not have any government that was either purely left-, or solely right-wing, and spent more than 27 years with neutral governments. However, the suggestion that apparently countries that spent the biggest fraction of our sample period under neutral governments can be associated with prosperous fiscal policies, is contradicted by the notion that also Belgium fits in this category. 
$<<<$ Insert tables (2) and (3) about here $>>>$

Table (3) shows the number of elections per country per decade. This variable will be used to draw inference on the presence of opportunistic behaviour by policy makers, and at the same time provides a proxy of the stability in the countries. However, we should note here that a low or moderate number of elections does not imply stability in terms of the durations of the government, since in our sample many regime changes occurred without elections taking place.

\section{Estimation Methodology: a Bayesian Framework}

Although the RCM described in equation 5 is structurally different from the more homogeneous panel data models that are most commonly used in the field of Political Economics, it can still be estimated using familiar OLS estimators. In particular, the Generalized Least Squares (GLS) estimator of $\bar{\beta}$ is its Best Linear Unbiased Estimator (c.f. Hsiao, 2003). However, given the increase in the number of estimated parameters, compared to a pooled model, the use of OLS methods comes with certain flaws. First, as shown by Hsiao, Pesaran and Tahmiscioglu (1999), the GLS estimator is considerably biased, particularly when the sample size is small. Second, due to the construction of the estimators, it provides us only with statistics on the mean over all countries, and the variability of this parameter. The information on country-specific estimates is limited to a combination of those two, but does not provide the opportunity to draw inference on particular estimates at the country-level and their variability. Given these shortcomings, the alternative estimation of the model in a Bayesian framework has some attractive advantages.

Hsiao, Pesaran and Tahmiscioglu (1999) have shown that Bayesian estimators have considerably smaller biases than OLS estimators when modeling a dynamic RCM. In part this is because Bayesian methods allow the modeler to use simulation methods, that reduce the burden coming from the limited amount of data that is available per country. Although in any case, the mean $\bar{\beta}$ is calculated over all countries, determination of the (variance) terms related to the country-specific parts of the coefficients $\alpha_{i}$ is based on just $T$ observations. Repeated simulations, like in Markov Chain Monte Carlo (MCMC) methods, provide a solution for this loss in accuracy, which becomes especially eminent when modeling shorter time periods.

The second advantage of Bayesian methods is that they allow for hierarchical estimation: according to whether they apply to all countries or to one 
country in particular, parameters can be simulated in different stages, such that e.g. the country-specific coefficients depend in part on the populationwide estimates. This point will be more pronounced in the next section, after the estimation methodology has been elicited.

A third advantage that comes together with the hierarchical structure of our estimations, is the possibility of increasing the number of parameters in our model, without posing additional demands on the available data; since in Bayesian methods, every coefficient estimate is defined by a probability distribution, rather than by a point estimate, the level, variability and dispersion of every coefficient (also the ones describing variance themselves) can be expressed and easily presented.

Finally, Bayesian methods provide elegant extensions to produce forecasts. Since estimation of a Bayesian model yields parameter distributions as outcome rather than point estimates, the parameter uncertainty and the degree of variability involved in its estimation are directly represented by the precision (or scale) of the relevant density function. Consequently, forecasts based on these parameter estimates directly incorporate the degree of parameter uncertainty and similarly acquire the form of a density function, with a shape that directly reflects its accuracy. This is in contrast with forecasts based on point estimates from traditional sampling methods, that do not directly incorporate the parameter uncertainty. Especially in the current context of budget deficits, the easily accessible option to provide forecasts will be interesting to explore, in order to evaluate the effect of potential changes in the political climate on the budgetary situation of the countries under consideration.

In order to enhance a better understanding of our later results, the next subsection will expose the Bayesian methodology employed in this paper, starting from a short introduction into Bayesian concepts in general. For a more detailed introduction into Bayesian econometrics, we refer the reader to textbooks such as Koop (2003), providing a very intuitive explanation, or Lancaster (2004).

\subsection{A Bayesian set-up}

Bayesian econometrics finds its roots in a common rule from probability theory, that plays such a central role in its methodology that its name is derived from it: Bayes' rule. For any two random variables $\theta$ and $z$, Bayes' rule states:

$$
p(\theta \mid z)=\frac{p(z \mid \theta) p(\theta)}{p(z)}
$$


where $p(\cdot \mid \cdot)$ denotes a conditional density and $p(\cdot)$ a marginal density. Now, interpretation of $\theta$ to be the parameters of our model and $z$ to be the data set the analysis is based on, yields the left hand side of expression (6) to represent the density of our parameters, conditional on the data. This is exactly the variable that Bayesian modelers are interested in, and in fact intuitively similar to the outcome of OLS methods: based on data one draws inference on particular parameters. At the same time, the expression $p(\theta \mid z)$ describes an essential difference between Bayesian econometrics on the one hand and more traditional frequentist methods on the other: Bayesian analyses have densities as outcome, rather than point estimates.

From the right hand side of expression (6), one can conclude that the density of interest is defined by three terms:

- $p(z \mid \theta)$, which is the likelihood function of the parameters $\theta$;

- $p(\theta)$, which is the marginal probability of the parameters;

- $p(z)$, which is the (marginal) likelihood function of the data under consideration.

This latter term does not involve the parameters of interest and therefore normalisation with respect to $p(z)$ has no effect on the findings for $p(\theta \mid z)$, such that:

$$
p(\theta \mid z) \propto p(z \mid \theta) p(\theta) .
$$

In this expression of proportionality, the last term $p(\theta)$ is what Bayesians typically call a prior density: it represents the beliefs of the modeler about the parameters prior to analysing the data. Similarly, the conditional density $p(\theta \mid z)$ obtained after analysing the data, is called posterior. Finally, the term $p(z \mid \theta)$ is the likelihood function that is familiar from other estimation techniques like Maximum Likelihood Estimation.

\subsubsection{Basic Assumptions}

Expression (7) reveals that the density of ultimate interest can, up to a proportionality factor, be obtained by calculating the product of the likelihood of the parameters and their prior. Therefore, the crucial assumptions underlying the analysis refer to these two terms. With respect to the first one, Bayesians start from a basic assumption that is most common in frequentist methods as well ${ }^{4}: \varepsilon_{m} \sim N\left(0, \sigma^{2}\right)$, and $\varepsilon_{m_{1}}$ and $\varepsilon_{m_{2}}$ are independent of each

\footnotetext{
${ }^{4}$ Results in this section are based on the following notation of a straightforward econometric model: $y_{m}=X_{m} \beta+\varepsilon_{m}, m=1: M$. Although this specification differs from the $\mathrm{RCM}$ exposed earlier, for the sake of transparency it is more convenient to present the model in a simplified version here, and add one dimension in the next subsection.
} 
other for $m_{1} \neq m_{2} \cdot{ }^{5}$ Using standard results from probability theory, this implies that also our dependent variable $y$ has a likelihood with a normal kernel.

Given the similarity between Bayesian methods and frequentist econometrics regarding the form of the likelihood function, the most controversial part of Bayesian methods is the prior density in the right hand side of expression (7). The choice for a particular functional form for this prior can have considerable impacts on the outcome of the analysis, the posterior density. However, as will be articulated later, particular distributional definitions can be chosen for the prior such that it does not influence the shape of the posterior distribution of the parameters: so-called uninformative priors.

Apart from its implications, the form of the chosen prior is of vital importance for the tractability of the results: multiplication of two probability density functions does by no means necessarily lead to a gentle posterior distribution. However, certain choices exist such that the resulting posterior becomes a neatly tractable function. In particular, selection of a natural conjugate prior, when combined with the Normal likelihood function, leads to a posterior with a similar kernel, i.e. to a posterior from the same distributional class. At this point, it is important to split the parameter set $\theta$ that has been considered so far, and specify two parts containing the elements $\beta$ and $\sigma^{-2}$, respectively. The latter term can be interpreted to be the precision of the error term and will be denoted $h$ throughout the rest of this introductory section. Then, the proportionality in expression (7) reads:

$$
p(\beta, h \mid z) \propto p(z \mid \beta, h) p(\beta, h)=p(z \mid \beta, h) p(\beta \mid h) p(h),
$$

using standard rules of probability. Referring to Koop (2003) for further details and references, we note here that, particularly motivated by the analytical tractability of the results, it is rather common to make the distinction between the model's coefficients $\beta$ and the precision of the error term. Besides, partitioning the parameter set is a convenient way to address specific variables of interest, and enables the modeler to specify particular distributional assumptions suited for the parameter he wants to focus on. In this context, it is a common choice to assume that the prior densities of $\beta$ and $h$ are independent of one another, such that $p(\beta \mid h)=p(\beta)$ in expression (8) and next define

$$
\beta \sim N(\underline{\beta}, \underline{V}) \text { and } h \sim G\left(\underline{s}^{-2}, \underline{v}\right) .
$$

Here, the bars underlining the parameters indicate that it concerns prior hyperparameters, to be defined by the modeler. Interestingly, the parameters

\footnotetext{
${ }^{5}$ These assumptions can be adapted to allow for e.g. heteroscedasticity and autocorrelation, without having essential consequences for the nature of the results.
} 
$\beta, \underline{s}^{-2}$ and $\underline{v}$ are the prior equivalents of the OLS estimators for $\beta$, standard errors and the degrees of freedom, respectively, and $V$ represents the prior expectation of the variance of $\beta$.

Based on these choices regarding the type of prior, and multiplying them with the normal likelihood of the dependent variable, the resulting joined posterior density of the parameters $\beta$ and $h, p(\beta, h \mid z)$, takes a non-convenient form. Therefore it will prove very convenient to express these posterior densities in a conditional form ${ }^{6}: p(\beta \mid h, y)$ and $p(h \mid \beta, y)$. As a consequence, all members of the other subclass(es) of the parameter set can be treated as constants, and the conditional densities prove to have very gentle forms: $p(\beta \mid h, y) \sim N(\cdot)$ and $p(h \mid \beta, y) \sim G(\cdot)$. The relevant location and scale parameters of these distributions will be described in the next subsection, after the current Bayesian model is adapted to the context of RCM.

\subsubsection{Simulations}

Conditioning the marginal densities of the parameters in the model on all other parameters in the model implies that posterior results will be interdependent. Since, in general, the posterior distributions cannot (all) be derived analytically, the typical Bayesian estimation approach uses simulation methods, for which the conditional posterior expressions provide very neat input arguments. They allow for taking subsequent draws from distributions that are more easily tractable, first for $\beta$ from the normal distribution depending on $h$, and next for $h$ from the Gamma-distribution conditional on the drawn value for $\beta$. Running this short algorithm repeatedly, one ends up with a path of draws for both variables, with all pairs depending on the latest draw of the other variable. This procedure is called Gibbs sampling. When increasing the number of simulations, convergence theorems imply that one obtains an approximation of the marginal densities $p(\beta \mid y)$ and $p(h \mid y)$, on which the interest of the exercise centers. The number of draws per iteration of the simulation can be increased, by dividing the parameter space into more than two subsets. ${ }^{7}$ Often, the estimation framework is rather complicated - e.g. due to inclusion of additional variables, or particular assumptions on their underlying structures, as is the case in RCM - leading to non-tractable joint posteriors, or the chosen prior does not yield appealing posterior functional forms. In those cases, having the opportunity of drawing simulations from

\footnotetext{
${ }^{6}$ Note that, whereas the priors for $\beta$ and $h$ are assumed to be independent, their posteriors are not, due to the multiplication by the likelihood of $z, p(z \mid \beta, h)$ in which both terms are included.

${ }^{7}$ As an example, when $\beta$ is a vector, one can define posteriors for every element conditional on all other elements in $\beta$ and $h$
} 
more tractable conditional posteriors is a very useful tool.

An additional advantage of employing a Bayesian estimation framework refers to the possibility to provide detailed posterior results on prediction of the dependent variable. The aim of such an exercise is to derive, from a hypothetical or forecasted data set $X^{*}$, a resulting set of values for the dependent variable $y^{*}$, based on the obtained posterior estimations for the parameters $\bar{\beta}$ :

$$
y^{*}=X^{*} \cdot \bar{\beta}+\varepsilon^{*} .
$$

Since the posterior of $\bar{\beta}$ is in fact a probability density function (and the posterior of $\epsilon$ too), consequently the following result for $y^{*}$ will also be a distribution, with predictive density:

$$
\begin{aligned}
p\left(y^{*} \mid z, X^{*}\right) & =\iint p\left(y^{*} \mid z, X^{*}, \beta, h\right) p\left(\beta, h \mid z, X^{*}\right) d \beta d h \\
& =\iint p\left(y^{*} \mid z, X^{*}, \beta, h\right) p(\beta, h \mid z) d \beta d h .
\end{aligned}
$$

Since the simulation methods described in the previous paragraph provided estimates for the posterior $p(\beta, h \mid z)$ in the right hand side of expression (10), the posterior predictive density of $y^{*}$ can directly be derived by using the draws for the posterior parameters in every iteration of the simulation and multiply them by $p\left(y^{*} \mid z, X^{*}, \beta, h\right)$, as a numerical approximation of the integrals in expression (11).

\subsection{Bayesian formulation of a RCM}

The simulation methods described above are one of the advantages of applying a Bayesian methodology. Another advantage described is the opportunity to incorporate hierarchical structures in the model. This is particularly sensible in the Random Coefficient Model under consideration in this paper, because we want to estimate country-specific parameters, but at the same time model an underlying pattern that applies to all countries. Returning to the formulation in equation (4), we assume that the country-specific parameters are normally distributed with:

$$
\beta_{i} \sim N\left(\mu_{\beta}, V_{\beta}\right)
$$

Here, different from the structure exposed in expression (9), $\mu_{\beta}$ and $V_{\beta}$ are not prior hyperparameters, but random variables themselves that have particular distributions. In this way, a second hierarchical stage is created, that links the draws for country-specific parameters and allows the country-specific 
estimates to 'borrow strength' from each other:

$$
\begin{aligned}
\mu_{\beta} & \sim N\left(\underline{\mu}_{\beta}, \underline{V}_{\beta}\right) \\
V_{\beta}^{-1} & \sim W\left(\nu_{\beta}, V_{\beta}^{-1}\right) .
\end{aligned}
$$

Again, the parameters with a lower bar are hyperparameters to be defined by the modeler. $W(\cdot)$ denotes the Wishart distribution ${ }^{8}$. In the next section we will focus on the impacts that particular choices will have. Finally, for the error precision we make the standard assumption:

$$
\sigma_{i}^{-2} \sim G\left(\underline{s}^{-2}, \underline{\nu}\right)
$$

Note that in this definition, we allow for heteroscedasticity and model countryspecific (inverted) variances. However, a priori, for all countries these are assumed to be drawn from the same distribution.

The appealing consequence of including a second stage is that for all parameters with a prior density (as opposed to a prior constant value), similarly a posterior density can be found. That gives us the opportunity to evaluate in one model the distributions of the country-specific parameters and the shape of their mean. Under the current choices of prior distributions, these posteriors have gentle forms, when presented conditionally. Following the notation in Koop (2003) and indicating parameters of posterior densities with an upper bar, we have for the country-specific parameters:

$$
\beta_{i} \mid y, \sigma_{1}^{-2}, \cdots, \sigma_{N}^{-2}, \mu_{\beta}, V_{\beta} \sim N\left(\bar{\beta}_{i}, \bar{V}_{i}\right),
$$

with

$$
\begin{gathered}
\bar{V}_{i}=\left(\sigma_{i}^{-2} X_{i}^{\prime} X_{i}+V_{\beta}^{-1}\right)^{-1} \\
\bar{\beta}_{i}=\bar{V}_{i}\left(\sigma_{i}^{-2} X_{i}^{\prime} y_{i}+V_{\beta}^{-1} \mu_{\beta}\right) .
\end{gathered}
$$

It is an instructive and fruitful exercise to observe the similarities between these Bayesian estimators and OLS statistics. The country-specific coefficients are drawn from a normal distribution with a mean $\bar{\beta}_{i}$ that depends on two types of terms. The first one are fixed inputs: data and the conditional parameters, as can be found in the first term between parentheses in the expressions for $\bar{V}_{i}$ and $\bar{\beta}_{i}$. The ratio of these two 'fixed' data terms is exactly the OLS estimator of the country-specific coefficients: $\widehat{\beta}_{i}=\left(X_{i}^{\prime} X_{i}\right)^{-1}\left(X_{i}^{\prime} y_{i}\right)$. Next to that, both the mean and variance of the distribution of $\beta_{i}$ contain another type of terms, that are not country-specific but rather population-wide.

\footnotetext{
${ }^{8}$ Here, the Wishart distribution is parameterized such that $E\left[V_{\beta}^{-1}\right]=\underline{\nu}_{\beta} \underline{V}_{\beta}^{-1}$
} 
Their values are obtained by draws from their particular distributions, that are obtained as a consequence of the prior assumptions we made. Turning to this second stage of the model, the relevant conditional posteriors densities for the hierarchical parameters are:

$$
\begin{aligned}
\mu_{\beta} \mid y, \beta, h, V_{\beta} & \sim N\left(\bar{\mu}_{\beta}, \bar{\Sigma}_{\beta}\right), \\
V_{\beta}^{-1} \mid y, \beta, h, \mu_{\beta} & \sim W\left(\bar{\nu}_{\beta},\left[\bar{\mu}_{\beta} \bar{V}_{\beta}\right]^{-1}\right),
\end{aligned}
$$

where

$$
\begin{aligned}
\bar{\Sigma}_{\beta} & =\left(N V_{\beta}^{-1}+\underline{\Sigma}_{\beta}^{-1}\right)^{-1} \\
\bar{\mu}_{\beta} & =\bar{\Sigma}_{\beta}\left(N V_{\beta}^{-1} \widetilde{\beta}+\underline{\Sigma}_{\beta}^{-1} \underline{\mu}_{\beta}\right) \\
\widetilde{\beta} & =\frac{\sum_{i=1}^{N} \beta_{i}}{N}
\end{aligned}
$$

and

$$
\begin{aligned}
\bar{\nu}_{\beta} & =N+\underline{\nu}_{\beta} \\
\bar{V}_{\beta} & =\sum_{i=1}^{N}\left(\beta_{i}-\mu_{\beta}\right)\left(\beta_{i}-\mu_{\beta}\right)^{\prime}+\underline{\nu}_{\beta} \underline{V}_{\beta} .
\end{aligned}
$$

Now the conditional distributions of the hierarchical components have been specified, one can further interpret the terms underlying expression (16). The posterior mean $\beta_{i}$ was seen to be partially dependent on data. The other determining factor is the overall mean $\mu_{\beta}$, that is drawn from a distribution with a posterior mean that also depends on two terms: the estimated mean $\widetilde{\beta}$ and the prior mean $\underline{\mu}_{\beta}$. Similar to the interpretation of the variables in the first stage, the actual posterior mean $\bar{\mu}_{\beta}$ is a weighted average of these two terms, with weights proportional to the relevant variances: $N V_{\beta}^{-1}$ and $\underline{\Sigma}_{\beta}^{-1}$, respectively. Similarly, in the construction of the posterior mean $\bar{\beta}_{i}$ of $\beta_{i}$, the two founding elements are weighted according to their (inverted) variance: the actual variation in the data $\sigma_{i}^{-2} X_{i}^{\prime} X_{i}$ and the simulated variance of $\mu_{\beta}$, $V_{\beta}$.

Finally, turning to the conditional posterior for the error precision, we assume heteroscedastic errors:

$$
\sigma_{i}^{-2} \mid y, \beta, \mu_{\beta}, V_{\beta} \sim G\left({\overline{s_{i}}}^{-2}, \bar{\nu}\right),
$$

with

$$
\begin{aligned}
\bar{\nu} & =T+\underline{\nu} \\
{\overline{s_{i}}}^{2} & =\frac{\left(y_{i}-X_{i} \beta_{i}\right)^{\prime}\left(y_{i}-X_{i} \beta_{i}\right)+\underline{\nu s^{2}}}{\bar{\nu}} .
\end{aligned}
$$


Although the introduction of hierarchical priors makes the overall model somewhat more diffuse, it is exactly this possibility to increase the number of parameters that makes it a powerful tool: since all results can be obtained by simulation methods, accuracy of the estimation is primarily dependent on the number of iterations, rather than the number of observations in the data set.

\subsection{Prior Elicitation}

For estimation of the Random Coefficient described in the previous section, we construct a model with hierarchical priors. The first step after formulating distributional assumptions on the priors, and deriving the resulting posterior densities as in the previous section, is to specify the particular values for the prior hyperparameter set $\left(\underline{\mu}_{\beta}, \underline{\Sigma}_{\beta}, \underline{\nu}_{\beta}, \underline{V}_{\beta}, \underline{\nu}, \underline{s}^{2}\right)$. As pointed out before, this is a rather controversial aspect of Bayesian methods. However, by choosing uninformative priors, the effect of the particular choices we make can be smoothed out, such that in the analyses, the terms depending on actual data dominate the results.

In order to see what values would qualify for this purpose, a short look at the equations concerning the hierarchical parameters suffices: $\underline{\mu}_{\beta}$ and $\underline{\Sigma}_{\beta}$ represent the prior mean and variance respectively. Choosing them small and large, respectively, minimises their effect on the posterior mean $\bar{\mu}_{\beta}$ and variance $\bar{\Sigma}_{\beta}$. Therefore, we choose $\underline{\mu}_{\beta}=0$ and $\underline{\Sigma}_{\beta}^{-1}=0.01 \times I_{K} \cdot{ }^{9}$

Regarding the variance of the overall mean, $\underline{\nu}_{\beta}$ is the prior sample size, referring to the country dimension. Since the actual number of countries under consideration is 15 , a (very) small prior will assign maximum weight to the terms depending on data. Analogously, a large value for the prior variance $\underline{V}_{\beta}$ of the country-specific parameter draws from their mean will be uninformative. Specifically, we take $\underline{\nu}_{\beta}=1$ and $\underline{V}_{\beta}=10 \times I_{K}$.

Finally, concerning the error precision, we select low degrees of freedom $\underline{\nu}=1$ and large prior variance $\underline{s}^{2}=25$.

\section{Empirical Results}

Using the conditional densities derived in the previous section, a Gibbs sampling algorithm can conveniently be applied to obtain posterior estimations of the several parameter sets in our model. Main interest here centers on the resulting approximations of the marginal posterior distributions, that are obtained using the conditional densities from expressions (16)-(19).

\footnotetext{
${ }^{9}$ Here, $I_{K}$ denotes the $(K \times K)$ identity matrix.
} 
$<<<$ Insert table (4) about here $>>>$

Columns 1-4 of table (4) present the summary statistics for the populationwide mean $\left(\mu_{\beta}\right)_{(K \times 1)}$ of the distribution from which the country-specific parameters will be drawn in the next hierarchical stage. The autoregressive persistence parameter has a mean estimated value of 0.835 and its $95 \%$ confidence interval is located above 0.75 , but considerably below the unit root value 1. Note here that in a Bayesian setting, inference is drawn based on the estimated density of a parameter, rather than a point estimate, and correspondingly a confidence interval is presented as the counterpart of a significance level. Therefore, the familiar t-test from frequentist methods on the significance of a parameter with level $\alpha$ finds its Bayesian equivalent in an evaluation of the location of the corresponding $\alpha$ confidence interval: if it is completely located in either the negative or the positive domain we reject the null hypothesis $H_{0}: \beta_{i, j}=0$.

Following this reasoning, table (4) shows that, in line with economic intuition, an increase of unemployment is strongly associated with an increase of the deficit, mainly via an increase in public expenditures. Similarly, economic acceleration brings along an increase in tax revenues that yields a decrease in the deficit. Both variables, capturing developments in the budget cycle, exhibit strong explanatory power, revealed by confidence intervals that are located and scaled well away from zero. On the other hand, the density mass of the posterior for the change in debt servicing costs is dispersed around zero. Although the mean effect is positive, in accordance with the argumentation that increasing costs will put the governmental budget under pressure, its magnitude cannot be distinguished from zero.

The degree of partisanship and the presence of political business cycles is captured by the two variables $I d e o_{i, t}$ and $E l e c_{i, t}$, respectively. The impact of ideology on the public deficit is small and widely dispersed around zero. On the other hand, results for the dummy variable on elections confirm the hypothesis that policymakers behave opportunistically rather than according to their partisanship and strongly reveal that deficits tend to be higher during election years. Finally, the mean of the posterior distribution for the dummy capturing the Maastricht effect is in line with the notion that the macroeconomic and fiscal restrictions that were imposed brought a general improvement in the budgetary situation for most participants. Although the confidence interval for the Maastricht-dummy includes the value zero, the probability mass of its posterior distribution is heavily located in the negative domain.

Finally, the fifth column of table (4) provides an estimate of the variation 
of the country-specific estimates from their mean. This parameter in fact relates to the second hierarchical stage, where the matrix $V_{\beta}$ as used after expression (16) assigns a weight to the population-wide mean, depending on the sum of the squared deviations of the country-specific parameters from this mean. The statistic presented in column 5 is this variance, scaled down by the number of countries $N$, to make it an interpretable variable. It is presented together with this first-stage posterior results since it provides a justification for our efforts to model heterogeneity between the countries' parameters, and its value should be compared to the mean from which it deviates. From the reported values, we can conclude that the persistence of the deficit and the effects of its economic determinants are similar among the countries in our set. Only the parameter on a change in unemployment shows notable dispersion from its mean, which can be attributed to differences in the social security systems in countries and the corresponding weight of unemployment transfers in the total expenditures by the government. Besides, structural differences in the volatility of unemployment cause the magnitude of its effect to be varying over the countries.

The parameters on political variables show a higher degree of variability among the countries. Especially the parameters on the effects of elections and the impact of the Maastricht effect appear, at the country-level, to have a high deviation from the population-wide mean. The index on ideology, having little impact on the deficit on average, shows a notable dispersion when compared to its mean and the precision of its confidence interval, suggesting that for particular countries the variable may possess explanatory power. Following these notions, the next subsection will present the summary statistics for the country-specific parameters.

$<<<$ Insert table (5) about here $>>>$

First, table (5) reports the posteriors estimates for the error precision $h_{i}$. Since this variable is defined as the inverse variance of the error term, a high value indicates high error precision and is an indicator of the goodness of fit of the model at the country level. Although the reported values are not very informative themselves, they do enable us to compare the heteroscedastic model to a model with a fixed error precision $h$. Doing this, we can observe that the average of the country-specific precisions reported in table (5) is considerably higher than the overall precision obtained when fixing it over all countries. ${ }^{10}$

\footnotetext{
${ }^{10}$ These latter results are not included in this paper, but are available from the authors upon request.
} 


\subsection{Country-specific effects}

Table (6) reports summary statistics on the posterior results for the countryspecific persistence parameters. In accordance with the notion from table (4) that there is little dispersion around its mean, differences between the country-specific values are small, and their means are all in the range [0.76-0.88]. Consideration of the confidence intervals reveals that the point 1 , the unit root value, is included in the $95 \%$ confidence interval for Spain, and just slightly excluded for Denmark and Finland, having similarly high mean parameters, and Luxembourg, having a flatter distribution. However, the presence of unit roots in our regressions would require major adaptations to the model specification, and from a theoretical perspective, the implications of non-stationary budget deficits would be unrealistic. Besides, it is beyond the scope of this paper to contribute to the ongoing debate in the literature regarding what are the most proper methods to analyse nonstationary processes in a panel data framework. Therefore, we suffice with the observation that for all countries, $95 \%$ of the probability mass is located below 0.98 , such that the null hypothesis $H_{0}: \beta_{i}=1$ can be rejected versus its alternative $H_{1}: \beta_{i}<1$.

$<<<$ Insert table (6) about here $>>>$

\subsubsection{Partisanship}

Table (7) reports posterior results on the variable capturing the impact of the ideological conviction of the government on the budget deficit. This variable allows us to draw inference on the extent to which policymakers show partisan behaviour. Since the partisan model focuses on the impact of ideology, it only provides guidance on the degree of explanatory power of the ideology variable; even when the partisan model indeed applies to our dataset, this does not tell much about the direction of this impact in our model that explains deficits. Although traditionally left-wing parties are associated with big governments (in terms of the share of their budget in a country's GDP), and right wing rulers with smaller governments, this applies to both the level of expenditures (including e.g. social security, subsidies) and to revenues (taxes). At the same time, leftist governments can be expected to be enhancing a Keynesian anti-cyclical policy that, when properly pursued, ensures that the surpluses created during prosperous times will cancel out the deficits built on during worse times. Therefore, in the long run these arguments do not provide a univocal rationale on the expected sign of the 
ideology variable.

$<<<$ Insert table (7) about here $>>>$

In line with the lack of more profound theoretical expectations on the direction of a partisan effect, results presented in the empirical literature suggest that government ideology is not a significant determinant of budget deficits. Our earlier findings in table (4) and results in the first column of table (7) confirm this notion: the posterior means of the estimates fluctuate around zero, and the country-level their absolute value is mostly smaller than 0.05. Besides, the last column of the table shows that for all countries, the confidence interval includes the point 0. However, for Sweden in particular, and for France to a lesser extent, one can observe that the posterior distribution of the parameter on the ideological index is strongly shifted to one side. Although the directions are opposite, this notion does provide a weak indication that in both countries the political conviction of the government can be linked to budgetary outcomes.

\subsubsection{Opportunistic Models and Political Business Cycles}

As an alternative for the hypothesis that policymakers act according to their ideological conviction when setting the budget, the opportunistic model states that governments tend to use the budget deficit as an instrument to please their electorate. Accordingly, on the eve of elections governments are expected to loosen their fiscal policy and increase the level of expenditures or allow a decrease in the tax revenues, in order to increase their chances for reelection accordingly, both resulting in an increase of the budget deficit. Indeed, the population mean of the election dummy-variable, as reported in table (4), reveals a strong positive link between elections and higher deficits. At the same time, the last column shows that there is a moderate degree of dispersion of the country-specific variables from their overall means. In order to evaluate the differences between particular countries, the parameter on the election dummy is presented at the country level in table (8).

$<<<$ Insert table (8) about here $>>>$

These results show that for 10 countries, the null hypothesis that there is no opportunistic effect can be rejected. For all countries except Belgium and Italy, more than $95 \%$ of the probability mass is located in the positive domain, which allows rejection of the same null hypothesis based on a 
one-sided test. ${ }^{11}$ The size of the opportunistic effect varies over countries. Interestingly, in Belgium and Italy, both among the countries with the highest average level of deficits, the positive effect of elections on the deficit is the smallest, with a mean parameter below 0.5. An intuitive explanation for this observation could be that the lack of budgetary strictness that other countries experienced particularly during election periods, characterised the policy of Belgium and Italy in general during large parts of the sample period. On the other hand, in Finland, having a great budgetary discipline with an average surplus of over $2.4 \%$, the deficit shows the strongest response to elections, with an increase of over $0.85 \%$.

\subsubsection{The Maastricht effect}

A first analysis of the time series of budget deficits showed that the European countries started to pursue policies of fiscal consolidation, or at least thoroughly improved their budgetary situation in the early 1990s. These developments took place in a period during which countries were subject to stricter measures and budget rules that were introduced in the Maastricht Treaty and would later become even more rigid; first in the Stability and Growth Pact and later upon entrance to the European Monetary Union. Since the Maastricht Treaty was the first agreement in the integration process that actually put constraints on the budgetary policies of the participating countries, a temporal dummy is included in the model that covers the change in the deficit resulting from enforcement of the Maastricht Treaty: Starting in 1994, and all years afterwards, it acquires the value of $1 .{ }^{12}$ Note here that attempts to model the other steps towards the EMU separately were fruitless, since the periods in between them are too short to provide us with sufficient data.

$<<<$ Insert table (9) about here $>>>$

Indeed the results in table (9) show that for most countries the Maastricht effect brought an improvement in their budgetary status. Besides, this effect was strongest for the countries that needed most improvement: Italy, Bel-

\footnotetext{
${ }^{11}$ This test, of which the results are not reported in the table, would be formulated as: $H_{0}: \beta_{i}=0$ vs. $H_{1}: \beta_{i}>0$.

${ }^{12}$ Although the Maastricht treaty was in fact signed in 1992 and went into force on 1 November 1993, its effects on the macro economies are likely to become present during the first year following its ratification. Besides, as of this year the convergence criteria applied.
} 
gium, Greece and Portugal are the countries with the highest average deficit over the sample, and are the only countries with a $95 \%$ confidence interval that is entirely smaller than 0. Ireland, the UK and the Netherlands, with average deficits between 2.5 and $4.5 \%$, follow in terms of magnitude of the Maastricht effect and its significance, with a density mass that is strongly located below zero by more than 94\%. On the other hand, Finland and Luxembourg show only minor, inconclusive responses following the Maastricht effect, but did not face the necessity to improve their budgetary status either. It is interesting to note that France and Germany show very little response to the Maastricht Treaty, although both had deficits larger than $3 \%$ in 1993. This absence of a clear quantitative effect is reflecting particularly the loosening of the budgetary policies of both countries in the early 2000s.

\subsection{Predicting Deficits}

In order to derive predictive posterior results, the country-specific densities presented in table (16) can be used in the way described in expression (11). In this section, predictive posterior results will be presented for France, for which the model performed best in terms of the error term precision. The hypothetical data $X^{*}$ on which the predictions will be based, are forecasts for the economic explanatory variables in the model over the years 20072009, obtained from the European Commission (EC, 2007). Besides, for the political variables, hypothetical data are created based on the situation in the country by the beginning of 2008 , that allow to run scenario analysis. ${ }^{13}$

Figure (7) presents a graphical representation of the posterior results. Starting from the observed deficit of $2.53 \%$, the blue line is a plot of the posterior mean results for the budget deficit, that slightly increases in election year 2007 to a value of $D e f_{F, 2007}^{*}=2.83$ and next gradually diminishes over the years 2008 and 2009 to 2.51 and 1.97, respectively. The dashed lines are the $95 \%$ confidence intervals of the predictive posterior distributions, revealing that there is a considerable probability that the deficit will exceed the $3 \%$ threshold, one of the critical pillars of the Stability and Growth Pact. The variability of the posterior estimates is driven by two types of precision: the precision related to the parameter estimates $\beta_{i}$ and the error term precision $h$.

$<<<$ Insert fig. (7) about here $>>>$

The red lines present a forecast for a different political scenario, assum-

\footnotetext{
${ }^{13}$ For the ideology index, a value of 2 represents the center-right orientation of the government. The election dummy acquires a value of one only in 2007 and finally the Maastricht dummy equals one over all three years.
} 
ing that the elections in 2007 would have been won by the socialist party. According to the posterior results of our model, the hypothesis that the parameter on the ideology index equals zero for France cannot be rejected, but nevertheless the vast majority of the probability mass of its posterior density function is located in the domain larger than zero. That implies that leftist governments, with a higher index value, tend to have higher deficits. This notion becomes directly apparent in figure (7), where the lines start in the same observed value in 2006 and then diverge. In 2007, the difference is only 0.12 percentage points, but now the deficit develops differently to subsequent values of 2.86 and 2.52. The divergence between the two scenarios comes from both the effect of ideology and, after 2007, from the persistence of the deficit, that in France is rather high around 0.86.

\section{Conclusion}

This paper presented a Random Coefficient Model to evaluate a set of economic and political determinants of budget deficits. This approach is considerably different from the standards in contemporary literature on this topic, to the extent that it allows for heterogeneity of all the parameters in the model. Although the vast majority of the European countries under consideration experienced deterioration of their budgetary situation following the oil crises in the 1970s, the level and persistence of these deficits varied heavily over the countries, even when they faced similar economic and political circumstances. This notion suggests that the roles of the various explanatory variables in a typical (political) macroeconomic model differ over the countries and consequently their coefficients should be allowed to vary. Indeed, results in this paper reveal a notable degree of heterogeneity between the countries, and call for the use of estimation methodologies that take this into account by providing additional flexibility.

At the same time, there exist similarities between the countries, and in particular the integration of the EU-15 after the ratification of the Maastricht Treaty stimulated convergence between the participating members. In our model this is specifically revealed by the persistence of deficits and the role of economic growth as a driving factor, that are rather homogeneous over the entire sample period. On the other hand, the impact of unemployment varies, reflecting differences in employed policies and structural differences in the level. Regarding the effect of political determinants, the empirical results reveal a greater degree of heterogeneity in their size, but similarities in terms of the explanatory power that the variables possess. More particular, the impact of ideology on the deficit is not evident. Its direction varies over the countries, but in any case the results show that the index on 
ideology is rather uninformative, due to a lack of precision of the posterior estimates. On the other hand, the opportunistic model strongly applies to our model, convincingly revealing an increase in the deficit during election years. Finally, countries acted differently on the requirements posed by the Maastricht Treaty, with efforts clearly related to the necessity to improve the budgetary situation.

The number of political variables in our model could be extended in future research, and their particular specification adjusted in order to enhance their informativeness and increase the explanatory power of the model. Suggestions for such adaptations can be found in other contemporaneous works on budget deficits (c.f. Mulas-Granados, 2007). As a contribution, this paper provided an estimation methodology that is novel in the field, and which yields results that convincingly reveal the needs to allow for heterogeneity even in a set of similar countries like the EU. Besides, the use of Bayesian Random Coefficient Methods is justified, being particularly gentle tools to carry out such analysis and providing a richness of estimation results that allow for considerably more detailed inference.

\section{References}

Alesina, A.,Perotti, R., 1995. The Political Economy of Budget Deficits. IMF Staff Papers 42 (1), 1-31.

Alesina, A. Perotti, R., 1996. Budget Deficits and Budget Institutions. NBER WP 5556.

Alesina, A., Roubini, N., 1997. Political Cycles and the Macroeconomy. The MIT Press, Cambridge, MA (US).

Andrikopoulos, A., Loizides, I., Prodromidis, K., 2004. Fiscal Policy and Political Business Cycles in the EU. European Journal of Political Economy 20, 125-152.

Ballabriga, F, Martinez-Mongay, C., 2005. Sustainability of EU Public Finances. European Economy - Economic Papers. European Commission (DC ECFIN) 225.

Barro, R., 1979. On the Determination of Public Debt. Journal of Political Economy 87, 940-971.

Beck, N., Katz, J., 1995. What to do (and not to do) with Time-Series 
Cross-Section Data. American Political Science Review 89, (3).

Buiter, W., Corsetti, G. , Roubini, N., 1993. Excessive deficits: Sense and Nonsense in the Treaty of Maastricht. Economic Policy 16, 58-100.

Edin, P., Ohlsson, H., 1994. Political Determinants of Budget Deficits: Coalition Effects versus Minority Effects. European Economic Review 35, 1597-1603.

Franzese, R., 2002. Electoral and Partisan Cycles in Economic Policies and Outcomes. Annual Review of Political Science 5, 369-421.

De Haan, J., Sturm, J., 1994. Political and Institutional Determinants of Fiscal Policy in the European Community. Public Choice 80 (1-2), 157-172.

European Commission, 2007. Economic Forecast Autumn 2007. European Economy 7.

Hsiao, C. 2003. Analysis of Panel Data. Cambridge University Press, UK.

Hsiao, C., Pesaran, M., Tahmiscioglu, A., 1999. Bayes Estimation of ShortRun Coefficients in Dynamic Panel Data Models. In: Hsiao, C., Lee, L., Lahiri, K., Pesaran, M. (Eds.). Analysis of Panels and Limited Dependent Variables Models. Cambridge University Press, Cambridge (UK), pp. 268296.

Koop, G., 2003. Bayesian Econometrics. John Wiley and Sons Inc.

Lancaster, T., 2004. An Introduction to Modern Bayesian Econometrics. Blackwell Publishing, Oxford.

Lucas, R., Stokey, N., 1983. Optimal Fiscal and Monetary Policy in an Economy without Capital. Journal of Monetary Economics 55, 55-93.

Mink, M., De Haan, J., 2005. Has the Stability and Growth Pact Impeded Political Budget Cycles in the European Union? CESifo WP 1532 (2).

Mulas-Granados, C., 2003. The Political and Economic Determinants of Budgetary Consolidation in Europe. European Political Economy Review 1 (1), 15-39. 
Perotti, R., Kontopoulos, Y., 2002. Fragmented Fiscal Policy. Journal of Public Economics 86, 191-222.

Roubini, N., 1995. The Economics of Fiscal Bondage: The Balanced Budget Amendment and Other Binding Fiscal Rules. Manuscript, Yale University.

Roubini, N., Sachs, J., 1989. Political and Economic Determinants of Budget Deficits in the Industrial Democracies. European Economic Review 33 (5), 903-938.

Swamy, P., 1970. Efficient Inference in a Random Coefficient Regression Model. Econometrica 38, 311-323.

Volkerink, B., De Haan, J., 2001. Fragmented Government Effects on Fiscal Policy: New Evidence. Public Choice 109 (3-4), 221-242.

Woldendorp, J., Keman, H., Budge, I., 2000. Party Government in 48 Democracies (1945-1998). Kluwer Academic Publishers, Dordrecht (NL).

Wooldridge, Jeffrey M., 2002. Econometric Analysis of Cross Section and Panel Data. The MIT Press, Cambridge, MA. 
Appendix: Tables and Figures

Table 1: Average Budget Balance per country per time period

\begin{tabular}{ccccccc} 
Year & $1971-1980$ & $1981-1990$ & $1991-2000$ & $2001-2006$ & $1970-1993$ & $1994-2006$ \\
\hline \hline Belgium & $-5,42$ & $-10,12$ & $-3,87$ & $-0,25$ & $-7,61$ & $-1,07$ \\
Denmark & 1,43 & $-1,91$ & $-1,41$ & 2,08 & $-0,72$ & 0,91 \\
Germany & $-2,01$ & $-2,01$ & $-2,30$ & $-3,19$ & $-2,15$ & $-2,55$ \\
Greece & $-1,35$ & $-10,36$ & $-8,24$ & $-5,39$ & $-6,81$ & $-5,69$ \\
Spain & $-0,58$ & $-4,45$ & $-4,10$ & 0,32 & $-2,98$ & $-1,49$ \\
France & $-0,29$ & $-2,38$ & $-3,69$ & $-2,99$ & $-1,89$ & $-3,02$ \\
Ireland & $-7,92$ & $-8,59$ & $-0,15$ & 1,01 & $-7,31$ & 1,25 \\
Italy & $-7,45$ & $-11,22$ & $-6,33$ & $-3,59$ & $-9,48$ & $-3,66$ \\
Luxembourg & 2,33 & 3,15 & 2,44 & 1,21 & 2,47 & 2,27 \\
Netherlands & $-1,49$ & $-4,96$ & $-1,91$ & $-1,14$ & $-3,23$ & $-1,07$ \\
Austria & $-0,87$ & $-3,20$ & $-3,12$ & $-1,00$ & $-2,28$ & $-1,92$ \\
Portugal & $-2,90$ & $-6,46$ & $-4,85$ & $-3,89$ & $-5,01$ & $-3,75$ \\
Finland & 4,93 & 3,98 & $-2,22$ & 3,41 & 2,82 & 1,65 \\
Sweden & 1,69 & $-0,79$ & $-3,54$ & 0,77 & $-0,85$ & $-0,12$ \\
UK & $-3,10$ & $-2,17$ & $-3,09$ & $-2,17$ & $-3,20$ & $-1,64$ \\
\hline EU-15 & 1,53 & 4,10 & 3,09 & 0,99 & 3,22 & 1,33 \\
\hline \hline
\end{tabular}


Table 2: Political Ideology: Fraction of time spent in each category per country

\begin{tabular}{cccccc} 
Country & \multicolumn{7}{c}{ Category } \\
\hline & 1 & 2 & 3 & 4 & 5 \\
\hline \hline Belgium & 21.6 & 2.7 & 75.7 & 0 & 0 \\
Denmark & 45.9 & 2.7 & 0 & 13.5 & 37.8 \\
Germany & 43.2 & 0 & 5.4 & 51.4 & 0 \\
Greece & 32.4 & 18.9 & 0 & 13.5 & 35.1 \\
Spain & 35.1 & 18.9 & 5.4 & 16.2 & 24.3 \\
France & 37.8 & 16.2 & 10.8 & 2.7 & 32.4 \\
Ireland & 54.1 & 35.1 & 10.8 & 0 & 0 \\
Italy & 16.2 & 62.2 & 8.1 & 13.5 & 0 \\
Luxembourg & 21.6 & 21.6 & 56.8 & 0 & 0 \\
Netherlands & 37.8 & 16.2 & 35.1 & 10.8 & 0 \\
Austria & 0 & 18.9 & 37.8 & 13.5 & 29.7 \\
Portugal & 32.4 & 16.2 & 16.2 & 21.6 & 13.5 \\
Finland & 0 & 10.8 & 75.7 & 13.5 & 0 \\
Sweden & 18.9 & 2.7 & 2.7 & 27 & 48.6 \\
UK & 51.4 & 2.7 & 2.7 & 21.6 & 21.6 \\
\hline EU-15 & 29.9 & 16.4 & 22.9 & 14.6 & 16.2 \\
\hline \hline
\end{tabular}


Table 3: Number of elections per decade

\begin{tabular}{cccccc} 
Country & \multicolumn{5}{c}{ Period } \\
\hline & $1971-1980$ & $1981-1990$ & $1991-2000$ & $2001-2006$ & Total \\
\hline \hline Belgium & 4 & 3 & 3 & 1 & 11 \\
Denmark & 5 & 5 & 2 & 2 & 14 \\
Germany & 3 & 3 & 2 & 2 & 10 \\
Greece & 2 & 4 & 3 & 1 & 10 \\
Spain & 2 & 3 & 3 & 1 & 9 \\
France & 2 & 3 & 2 & 1 & 8 \\
Ireland & 2 & 4 & 2 & 1 & 9 \\
Italy & 3 & 2 & 3 & 2 & 10 \\
Luxembourg & 2 & 2 & 2 & 1 & 7 \\
Netherlands & 3 & 4 & 2 & 2 & 11 \\
Austria & 3 & 3 & 3 & 1 & 10 \\
Portugal & 5 & 3 & 3 & 2 & 13 \\
Finland & 3 & 2 & 3 & 1 & 9 \\
Sweden & 3 & 3 & 3 & 2 & 11 \\
UK & 2 & 2 & 2 & 2 & 8 \\
\hline EU-15 & 2.9 & 3.1 & 2.5 & 1.5 & 10 \\
\hline \hline
\end{tabular}


Table 4: Posterior estimates for meta distribution $\mu_{\beta}$

Posterior mean, standard deviation, and 95\% confidence interval for $\mu_{\beta}$, which is the mean impact of the explanatory variables over all countries, with

$$
\mu_{\beta} \sim N\left(\bar{\mu}_{\beta}, \bar{\Sigma}_{\beta}\right) .
$$

Statistic

\begin{tabular}{ccccc}
\hline Variable & Mean & s.d. & $95 \%$ C.I. & $\sigma_{\alpha_{i}}^{2}$ \\
\hline \hline$D E F_{i, t}$ & 0.835 & 0.038 & {$[0.757,0.911]$} & 0.006 \\
$\Delta U B_{i, t}$ & 0.546 & 0.139 & {$[0.270,0.825]$} & 0.091 \\
$\Delta y_{i, t}$ & -0.110 & 0.043 & {$[-0.196,-0.025]$} & 0.007 \\
$D R B_{i, t}$ & 0.012 & 0.052 & {$[-0.096,0.110]$} & 0.010 \\
\hline Ideo $_{i, t}$ & -0.023 & 0.093 & {$[-0.220,0.151]$} & 0.038 \\
Elec $_{i, t}$ & 0.627 & 0.179 & {$[0.278,0.973]$} & 0.088 \\
$\delta_{M}$ & -0.420 & 0.233 & {$[-0.894,0.016]$} & 0.202 \\
$c$ & 0.461 & 0.384 & {$[-0.262,1.270]$} & 0.762 \\
\hline \hline
\end{tabular}


Table 5: Posterior estimates for error precision parameters $h$

Posterior mean, standard deviation, and $95 \%$ confidence interval for $h_{i}$, which is the heteroscedastic error precision defined as $h_{i}=\sigma_{i}^{-2}$ and has distribution:

$$
\sigma_{i}^{-2} \sim G\left({\overline{s_{i}}}^{-2}, \bar{v}\right)
$$

Statistic

\begin{tabular}{cccc}
\hline Country & Mean & s.d. & $95 \%$ C.I. \\
\hline \hline Belgium & 0.435 & 0.110 & {$[0.249,0.675]$} \\
Denmark & 0.446 & 0.111 & {$[0.254,0.688]$} \\
Germany & 0.669 & 0.176 & {$[0.373,1.059]$} \\
Greece & 0.289 & 0.075 & {$[0.162,0.452]$} \\
Spain & 1.002 & 0.256 & {$[0.564,1.565]$} \\
France & 1.838 & 0.477 & {$[1.027,2.882]$} \\
Ireland & 0.302 & 0.075 & {$[0.173,0.465]$} \\
Italy & 0.664 & 0.179 & {$[0.367,1.068]$} \\
Luxembourg & 0.273 & 0.068 & {$[0.160,0.422]$} \\
Netherlands & 0.734 & 0.185 & {$[0.417,1.146]$} \\
Austria & 1.119 & 0.284 & {$[0.636,1.745]$} \\
Portugal & 0.432 & 0.109 & {$[0.248,0.667]$} \\
Finland & 0.370 & 0.095 & {$[0.210,0.575]$} \\
Sweden & 0.317 & 0.090 & {$[0.170,0.519]$} \\
UK & 0.513 & 0.130 & {$[0.293,0.796]$} \\
\hline \hline
\end{tabular}


Table 6: Posterior estimates for country-specific persistence parameters

Posterior mean, standard deviation, and $95 \%$ confidence interval for the elements of $\beta_{i}$ related to persistence:

$$
y_{i, t}=\beta_{i} \cdot D E F_{i, t}+\sum_{j} \beta_{j} \cdot X_{-D E F}
$$

Statistic

\begin{tabular}{cccc}
\hline Country & Mean & s.d. & $95 \%$ C.I. \\
\hline \hline Belgium & 0.849 & 0.061 & {$[0.727,0.968]$} \\
Denmark & 0.879 & 0.059 & {$[0.766,0.999]$} \\
Germany & 0.763 & 0.092 & {$[0.550,0.915]$} \\
Greece & 0.864 & 0.054 & {$[0.757,0.968]$} \\
Spain & 0.878 & 0.062 & {$[0.757,1.003]$} \\
France & 0.858 & 0.062 & {$[0.731,0.980]$} \\
Ireland & 0.844 & 0.056 & {$[0.731,0.955]$} \\
Italy & 0.828 & 0.065 & {$[0.697,0.950]$} \\
Luxembourg & 0.856 & 0.067 & {$[0.719,0.984]$} \\
Netherlands & 0.828 & 0.067 & {$[0.693,0.961]$} \\
Austria & 0.804 & 0.065 & {$[0.673,0.929]$} \\
Portugal & 0.812 & 0.064 & {$[0.679,0.932]$} \\
Finland & 0.874 & 0.057 & {$[0.761,0.988]$} \\
Sweden & 0.790 & 0.065 & {$[0.658,0.915]$} \\
UK & 0.792 & 0.067 & {$[0.650,0.913]$} \\
\hline \hline
\end{tabular}


Table 7: Posterior estimates for country-specific parameters on ideology

Posterior mean, standard deviation, and 95\% confidence interval for the elements of $\beta_{i}$ related to government ideology.

$$
y_{i, t}=\beta_{i} \cdot I D E O_{i, t}+\sum_{j} \beta_{j} \cdot X_{-I D E O} .
$$

\begin{tabular}{cccc}
\multicolumn{5}{c}{ Statistic } \\
\hline Country & Mean & s.d. & $95 \%$ C.I. \\
\hline \hline Belgium & -0.012 & 0.183 & {$[-0.382,0.353]$} \\
Denmark & 0.054 & 0.116 & {$[-0.170,0.292]$} \\
Germany & 0.032 & 0.116 & {$[-0.201,0.261]$} \\
Greece & 0.047 & 0.139 & {$[-0.220,0.327]$} \\
Spain & 0.090 & 0.103 & {$[-0.111,0.295]$} \\
France & 0.123 & 0.074 & {$[-0.023,0.270]$} \\
Ireland & -0.030 & 0.175 & {$[-0.393,0.310]$} \\
Italy & -0.147 & 0.216 & {$[-0.609,0.237]$} \\
Luxembourg & 0.006 & 0.196 & {$[-0.385,0.410]$} \\
Netherlands & -0.037 & 0.131 & {$[-0.318,0.205]$} \\
Austria & 0.000 & 0.138 & {$[-0.275,0.280]$} \\
Portugal & -0.013 & 0.134 & {$[-0.288,0.245]$} \\
Finland & -0.052 & 0.238 & {$[-0.547,0.425]$} \\
Sweden & -0.327 & 0.199 & {$[-0.748,0.024]$} \\
UK & -0.074 & 0.113 & {$[-0.307,0.136]$} \\
\hline \hline
\end{tabular}


Table 8: Posterior estimates for country-specific parameters on effect of elections

Posterior mean, standard deviation, and $95 \%$ confidence interval for the elements of $\beta_{i}$ related to government ideology.

$$
y_{i, t}=\beta_{i} \cdot\left(\delta_{\text {elec }}\right)_{i, t}+\sum_{j} \beta_{j} \cdot X_{-\delta_{\text {elec }}} .
$$

\begin{tabular}{cccc}
\hline Country & Mean & s.d. & $95 \%$ C.I. \\
\hline \hline Belgium & 0.494 & 0.296 & {$[-0.146,1.026]$} \\
Denmark & 0.700 & 0.274 & {$[0.184,1.268]$} \\
Germany & 0.577 & 0.259 & {$[0.049,1.074]$} \\
Greece & 0.701 & 0.303 & {$[0.141,1.385]$} \\
Spain & 0.526 & 0.254 & {$[0.009,1.022]$} \\
France & 0.669 & 0.219 & {$[0.243,1.108]$} \\
Ireland & 0.540 & 0.273 & {$[-0.051,1.038]$} \\
Italy & 0.467 & 0.330 & {$[-0.197,1.109]$} \\
Luxembourg & 0.615 & 0.319 & {$[-0.047,1.243]$} \\
Netherlands & 0.558 & 0.234 & {$[0.083,1.002]$} \\
Austria & 0.750 & 0.234 & {$[0.311,1.239]$} \\
Portugal & 0.569 & 0.254 & {$[0.031,1.051]$} \\
Finland & 0.866 & 0.357 & {$[0.224,1.660]$} \\
Sweden & 0.729 & 0.384 & {$[-0.030,1.495]$} \\
UK & 0.613 & 0.254 & {$[0.095,1.107]$} \\
\hline \hline
\end{tabular}


Table 9: Posterior estimates for country-specific parameters on Maastricht effect

Posterior mean, standard deviation, and 95\% confidence interval for the elements of $\beta_{i}$ related to government ideology.

$$
y_{i, t}=\beta_{i} \cdot\left(\delta_{M}\right)_{i, t}+\sum_{j} \beta_{j} \cdot X_{-\delta_{M}} .
$$

\begin{tabular}{|c|c|c|c|}
\hline Country & Mean & s.d. & 95\% C.I. \\
\hline Belgium & "-0.741 & 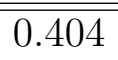 & 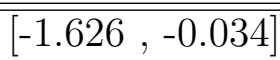 \\
\hline Denmark & -0.148 & 0.317 & {$[-0.749$} \\
\hline Germany & -0.196 & 0.298 & {$[-0.760$} \\
\hline Greece & -0.678 & 0.392 & {$[-1.539$} \\
\hline Spain & -0.375 & 0.283 & {$[-0.927$} \\
\hline France & -0.079 & 0.255 & {$[-0.570$} \\
\hline Ireland & -0.595 & 0.361 & {$[-1.385,0.048]$} \\
\hline Italy & -0.987 & 0.461 & {$[-1.951,-0.176]$} \\
\hline Luxem & -0.121 & 0.372 & {$[-0.820,0.682]$} \\
\hline Netherlands & -0.479 & 0.272 & {$[-1.025,0.047]$} \\
\hline Aust & -0.354 & 0.314 & {$[-0.987,0.267]$} \\
\hline Port & -0.613 & 0.318 & {$[-1.296,-0.037]$} \\
\hline Finl & 0.003 & 0.427 & {$[-0.765,0.908]$} \\
\hline Swec & -0.452 & 0.436 & {$[-1.331,0.426]$} \\
\hline UK & -0.463 & 0.303 & {$[-1.067,0.146]$} \\
\hline
\end{tabular}




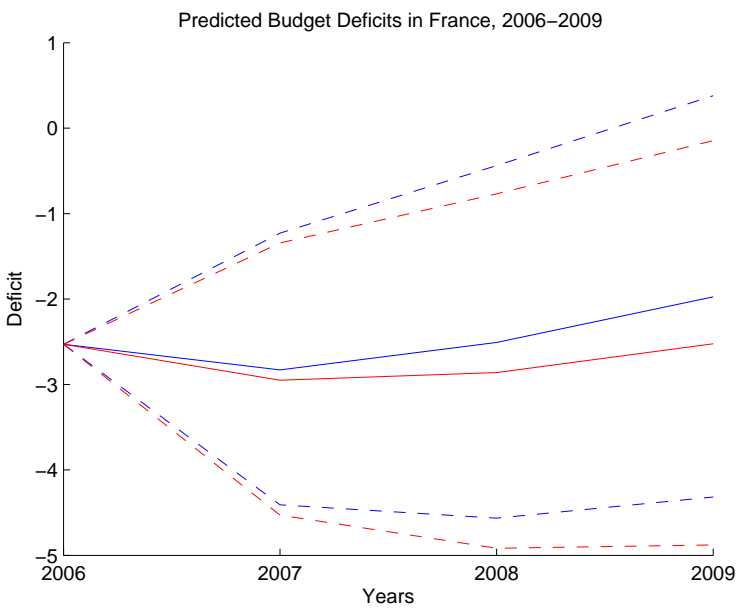

Figure 1:

Predicted Budget Deficits in France, 2007-2009 


\section{CESifo Working Paper Series}

for full list see www.cesifo-group.org/wp

(address: Poschingerstr. 5, 81679 Munich, Germany, office@cesifo.de)

2485 Irani Arraiz, David M. Drukker, Harry H. Kelejian and Ingmar R. Prucha, A Spatial Cliff-Ord-type Model with Heteroskedastic Innovations: Small and Large Sample Results, December 2008

2486 Oliver Falck, Michael Fritsch and Stephan Heblich, The Apple doesn't Fall far from the Tree: Location of Start-Ups Relative to Incumbents, December 2008

2487 Cary Deck and Harris Schlesinger, Exploring Higher-Order Risk Effects, December 2008

2488 Michael Kaganovich and Volker Meier, Social Security Systems, Human Capital, and Growth in a Small Open Economy, December 2008

2489 Mikael Elinder, Henrik Jordahl and Panu Poutvaara, Selfish and Prospective: Theory and Evidence of Pocketbook Voting, December 2008

2490 Maarten Bosker and Harry Garretsen, Economic Geography and Economic Development in Sub-Saharan Africa, December 2008

2491 Urs Fischbacher and Simon Gächter, Social Preferences, Beliefs, and the Dynamics of Free Riding in Public Good Experiments, December 2008

2492 Michael Hoel, Bush Meets Hotelling: Effects of Improved Renewable Energy Technology on Greenhouse Gas Emissions, December 2008

2493 Christian Bruns and Oliver Himmler, It's the Media, Stupid - How Media Activity Shapes Public Spending, December 2008

2494 Andreas Knabe and Ronnie Schöb, Minimum Wages and their Alternatives: A Critical Assessment, December 2008

2495 Sascha O. Becker, Peter H. Egger, Maximilian von Ehrlich and Robert Fenge, Going NUTS: The Effect of EU Structural Funds on Regional Performance, December 2008

2496 Robert Dur, Gift Exchange in the Workplace: Money or Attention?, December 2008

2497 Scott Alan Carson, Nineteenth Century Black and White US Statures: The Primary Sources of Vitamin D and their Relationship with Height, December 2008

2498 Thomas Crossley and Mario Jametti, Pension Benefit Insurance and Pension Plan Portfolio Choice, December 2008

2499 Sebastian Hauptmeier, Ferdinand Mittermaier and Johannes Rincke, Fiscal Competition over Taxes and Public Inputs: Theory and Evidence, December 2008 
2500 Dirk Niepelt, Debt Maturity without Commitment, December 2008

2501 Andrew Clark, Andreas Knabe and Steffen Rätzel, Boon or Bane? Others' Unemployment, Well-being and Job Insecurity, December 2008

2502 Lukas Menkhoff, Rafael R. Rebitzky and Michael Schröder, Heterogeneity in Exchange Rate Expectations: Evidence on the Chartist-Fundamentalist Approach, December 2008

2503 Salvador Barrios, Harry Huizinga, Luc Laeven and Gaëtan Nicodème, International Taxation and Multinational Firm Location Decisions, December 2008

2504 Andreas Irmen, Cross-Country Income Differences and Technology Diffusion in a Competitive World, December 2008

2505 Wenan Fei, Claude Fluet and Harris Schlesinger, Uncertain Bequest Needs and LongTerm Insurance Contracts, December 2008

2506 Wido Geis, Silke Uebelmesser and Martin Werding, How do Migrants Choose their Destination Country? An Analysis of Institutional Determinants, December 2008

2507 Hiroyuki Kasahara and Katsumi Shimotsu, Sequential Estimation of Structural Models with a Fixed Point Constraint, December 2008

2508 Barbara Hofmann, Work Incentives? Ex Post Effects of Unemployment Insurance Sanctions - Evidence from West Germany, December 2008

2509 Louis Hotte and Stanley L. Winer, The Demands for Environmental Regulation and for Trade in the Presence of Private Mitigation, December 2008

2510 Konstantinos Angelopoulos, Jim Malley and Apostolis Philippopoulos, Welfare Implications of Public Education Spending Rules, December 2008

2511 Robert Orlowski and Regina T. Riphahn, The East German Wage Structure after Transition, December 2008

2512 Michel Beine, Frédéric Docquier and Maurice Schiff, International Migration, Transfers of Norms and Home Country Fertility, December 2008

2513 Dirk Schindler and Benjamin Weigert, Educational and Wage Risk: Social Insurance vs. Quality of Education, December 2008

2514 Bernd Hayo and Stefan Voigt, The Relevance of Judicial Procedure for Economic Growth, December 2008

2515 Bruno S. Frey and Susanne Neckermann, Awards in Economics - Towards a New Field of Inquiry, January 2009

2516 Gregory Gilpin and Michael Kaganovich, The Quantity and Quality of Teachers: A Dynamic Trade-off, January 2009 
2517 Sascha O. Becker, Peter H. Egger and Valeria Merlo, How Low Business Tax Rates Attract Multinational Headquarters: Municipality-Level Evidence from Germany, January 2009

2518 Geir H. Bjønnes, Steinar Holden, Dagfinn Rime and Haakon O.Aa. Solheim, ,Large’ vs. ,Small' Players: A Closer Look at the Dynamics of Speculative Attacks, January 2009

2519 Jesus Crespo Cuaresma, Gernot Doppelhofer and Martin Feldkircher, The Determinants of Economic Growth in European Regions, January 2009

2520 Salvador Valdés-Prieto, The 2008 Chilean Reform to First-Pillar Pensions, January 2009

2521 Geir B. Asheim and Tapan Mitra, Sustainability and Discounted Utilitarianism in Models of Economic Growth, January 2009

2522 Etienne Farvaque and Gaël Lagadec, Electoral Control when Policies are for Sale, January 2009

2523 Nicholas Barr and Peter Diamond, Reforming Pensions, January 2009

2524 Eric A. Hanushek and Ludger Woessmann, Do Better Schools Lead to More Growth? Cognitive Skills, Economic Outcomes, and Causation, January 2009

2525 Richard Arnott and Eren Inci, The Stability of Downtown Parking and Traffic Congestion, January 2009

2526 John Whalley, Jun Yu and Shunming Zhang, Trade Retaliation in a Monetary-Trade Model, January 2009

2527 Mathias Hoffmann and Thomas Nitschka, Securitization of Mortgage Debt, Asset Prices and International Risk Sharing, January 2009

2528 Steven Brakman and Harry Garretsen, Trade and Geography: Paul Krugman and the 2008 Nobel Prize in Economics, January 2009

2529 Bas Jacobs, Dirk Schindler and Hongyan Yang, Optimal Taxation of Risky Human Capital, January 2009

2530 Annette Alstadsæter and Erik Fjærli, Neutral Taxation of Shareholder Income? Corporate Responses to an Announced Dividend Tax, January 2009

2531 Bruno S. Frey and Susanne Neckermann, Academics Appreciate Awards - A New Aspect of Incentives in Research, January 2009

2532 Nannette Lindenberg and Frank Westermann, Common Trends and Common Cycles among Interest Rates of the G7-Countries, January 2009

2533 Erkki Koskela and Jan König, The Role of Profit Sharing in a Dual Labour Market with Flexible Outsourcing, January 2009 
2534 Tomasz Michalak, Jacob Engwerda and Joseph Plasmans, Strategic Interactions between Fiscal and Monetary Authorities in a Multi-Country New-Keynesian Model of a Monetary Union, January 2009

2535 Michael Overesch and Johannes Rincke, What Drives Corporate Tax Rates Down? A Reassessment of Globalization, Tax Competition, and Dynamic Adjustment to Shocks, February 2009

2536 Xenia Matschke and Anja Schöttner, Antidumping as Strategic Trade Policy Under Asymmetric Information, February 2009

2537 John Whalley, Weimin Zhou and Xiaopeng An, Chinese Experience with Global 3G Standard-Setting, February 2009

2538 Claus Thustrup Kreiner and Nicolaj Verdelin, Optimal Provision of Public Goods: A Synthesis, February 2009

2539 Jerome L. Stein, Application of Stochastic Optimal Control to Financial Market Debt Crises, February 2009

2540 Lars P. Feld and Jost H. Heckemeyer, FDI and Taxation: A Meta-Study, February 2009

2541 Philipp C. Bauer and Regina T. Riphahn, Age at School Entry and Intergenerational Educational Mobility, February 2009

2542 Thomas Eichner and Rüdiger Pethig, Carbon Leakage, the Green Paradox and Perfect Future Markets, February 2009

2543 M. Hashem Pesaran, Andreas Pick and Allan Timmermann, Variable Selection and Inference for Multi-period Forecasting Problems, February 2009

2544 Mathias Hoffmann and Iryna Shcherbakova, Consumption Risk Sharing over the Business Cycle: the Role of Small Firms' Access to Credit Markets, February 2009

2545 John Beirne, Guglielmo Maria Caporale, Marianne Schulze-Ghattas and Nicola Spagnolo, Volatility Spillovers and Contagion from Mature to Emerging Stock Markets, February 2009

2546 Ali Bayar and Bram Smeets, Economic and Political Determinants of Budget Deficits in the European Union: A Dynamic Random Coefficient Approach, February 2009 